\title{
Analysis of the State Universal Basic Education Board's Execution of Strategic Capacity Building and Teachers' Job Satisfaction in Akwa Ibom State, Nigeria
}

Affiong Imeh Imeh: Department of Curriculum Studies, Educational Management Planning, Faculty of Education, University of Uyo, Uyo, Akwa Ibom State, Nigeria.

\begin{abstract}
This study examined the relationship between the State Universal Basic Education Board's execution of strategic capacity building and teachers' job satisfaction in Akwa Ibom State. One objective, research question and null hypothesis were formulated to guide the study. The correlational design was adopted. The population of the study consisted of 12,566 public primary school teachers in Akwa Ibom State. A multi-stage approach was used to select a sample size of 1,750 teachers. Two researcher-developed instruments namely 'Executing Strategic Capacity Building Questionnaire (ESCBQ) and 'Teachers' Job Satisfaction Questionnaire (TJSQ)' were both completed by teachers and used for data collection. The instruments were validated by three experts from the University of Uyo. The Cronbach's Alpha Statistic was used to ascertain the reliability coefficients of .832 and .790 respectively. Correlation $(r)$ was used to answer research question while the PPMC analysis was used to test hypothesis at 0.05 level of significance. The findings revealed that strategic capacity building has a significant relationship with teachers' job satisfaction. It is therefore recommended that SUBEB management should strategically design and carryout capacity building programmes for teachers based on needs assessment that leads to successful implementation of educational strategies.
\end{abstract}

Key words: Strategy execution, Capacity building, Job satisfaction.

\section{Introduction}

From the Federal Republic of Nigeria (2004) the section 9 of the Universal Basic Education Act provides for the implementation of the Universal Basic Education programme through the State Universal Basic Education Board (SUBEB) of each of the 36 states in Nigeria. The functions of SUBEB are translated into workable strategies for implementation. Each feasible strategy is broken down into institutional schedules, phases, objectives, target groups, events and expected outcomes. Akon (2016) highlighted Nigeria's most recent education strategic plan titled, 'Education for Change: A Ministerial Strategic Plan 2016-2019. The plan seeks to address various gaps in the education sector such as global reports of low basic education quality which show Nigeria's primary school children performance as the worst out of 22 Sub-Saharan and North African countries (Psacharopoulous, 2016). One of the strategies of 'Education for Change' includes retraining existing teachers for quality delivery. This is capacity building and it involves building and strengthening teachers' skills, knowledge, attributes, dispositions, competences and capabilities through trainings and staff development programmes. Osuji (2014) opined that teachers are the field agents of educational change and reform therefore, the necessity of making strategic plans to build human capacity and knowledge through comprehensive and high quality education, training and skills development programs cannot be overstated.

Studies

Vol. 2, No.2, pp. 85-90

2019

$2641-533 x . v 2 i 2.108$ Funding: This study received no specific financial support.

Received: 19 March 2019

Revised: 30 April 2019

Accepted: 2 July 2019

(C) 2019 by the authors; licensee Academic

Publishing Group 
The researcher's interest grew out of concern for Nigeria's recent ratings of the state of basic education. This shows that implementations of past strategic education plans had yielded little or no results. Formulation to implementation of strategies goes through strategic management process. Pederson (2008) observed that reviews on strategy management processes consistently include strategic analysis, strategic formulation and strategy implementation while strategy execution is absent from contemporary literature. Rosenzweig and Tubiello (2007) in Pederson (2008) declared strategy execution as unaddressed and the biggest obstacle to success. Strategy execution was proposed as the missing link between formulation and implementation in order to make strategy implementation successful.

Strategy execution is an emerging area and an aspect that is lacking in educational research and management in Nigeria. Performance Factory (2010) revealed that the strategy execution report for 2009/2010 covered only two countries from Africa (Egypt and South Africa) and the education sector represented less than two percent of total organizations studied. Surveys used for strategy execution research report assessed execution capabilities based on eight perspectives: strategy focus; strategy communication; initiative management; individual objective setting; skilled managers; engaged people and performance-driven culture; performance- related pay; and support for managers (Flander, 2015). The strategy execution research revealed that major implementation challenges were caused by significant execution gaps. This may also be attributed to implementation setbacks of Nigeria's strategic education plans and this study proposes that educational strategies should be executed before implemented. Items on the instrument for SUBEB's execution of strategic teacher capacity building are structured based on the eight perspectives. Akpan and Ita (2015) examined 'Teacher Professional Development and Quality Universal Basic Education in Lagos State, Nigeria'. The findings of the study revealed that teacher participation in induction programmes, ICT trainings and participation in seminars/workshops significantly relate to quality universal basic education and recommended the provision of opportunities to teachers to update their skills for higher productivity. Based on prior researches, this study takes a step ahead on how to strategically execute those recommendations on capacity building before actual implementation. Execution of strategies cannot be achieved in a vacuum because organizational procedures link with the work of individuals. This study seeks to establish how SUBEB's execution of strategic capacity building relates with teachers' job satisfaction in Akwa Ibom state.

\subsection{Statement of Problem}

Series of implementations of Nigeria's strategic educational plans have taken place without achieving the educational targets at national and global levels. Strategic education plans seem to fail at the implementation stage which may be due to lack of knowledge of the processes of strategy execution. Educational managers may still fail to achieve the on-going strategy for quality delivery of basic education through teacher capacity building if this gap persists. This may have resulted in low levels of job satisfaction experienced by basic education teachers as observed in their high rates of absenteeism, turnover and attrition. It is against this backdrop that this study seeks to determination the relationship between SUBEB's execution of strategic capacity building and teachers' job satisfaction in Akwa Ibom state.

\subsection{Purpose of the Study}

The purpose of the study was to determine the relationship between the State Universal Basic Education Board's execution of strategic capacity building and teachers job satisfaction in Akwa Ibom State, Nigeria.

International Journal of Educational Studies

Vol. 2, No.2, pp. 85-90

2019

DOI: $10.53935 / 2641-533 x . v 2 i 2.108$

Funding: This study received no specific

financial support.

Article History:

Received: 19 March 2019

Revised: 30 April 2019

Accepted: 2 July 2019

Published: 26 August 2019

(c) 2019 by the authors; licensee Academic

Publishing Group

\subsection{Research Question}

What is the relationship between SUBEB's execution of strategic capacity building and teachers' job satisfaction in Akwa Ibom State, Nigeria?

\subsection{Research Hypothesis}

There is no significant relationship between SUBEB's execution of strategic capacity building and teachers' job satisfaction in Akwa Ibom State, Nigeria. 


\section{Literature Review}

Strategy execution is a managerial concept used in multi-national companies and the universality of management makes it possible for its application in educational organizations like SUBEB. Favaro (2015) viewed strategy execution as decisions and activities undertaken in order to turn strategy into a success. Pederson (2008) listed two key elements of strategy execution process as translation and adaptation. The author viewed translation as a workable blueprint and comprehensive roadmap for execution that must provide a communication plan, a coordination plan and a resource allocation plan. Adaptation aligns strategy with reality by conducting surveys, analyses, pilot tests which creates room to ascertain feasibility of strategy and adjustments.

Capacity building is not about the buildup of knowledge and skills for their own sake, but about how they will be used and the changes that will result. Strategic capacity building builds the right capacities, for the right people, and at the right time. Gordon and Chadwick (2007) viewed capacity building as an integral part of development assistance that seeks to build the understanding, skills and knowledge base of individuals and institutions. The authors identified three processes required for strategic capacity building. The processes are assessing capacity needs, designing appropriate interventions and determining results.

Assessment of capacity needs involves a needs analysis that identifies and determines the type of capacity that needs to be built in teachers. The element of translation enables SUBEB managers prepare blue-print of the strategic three-year vision and annual targets for teacher capacity building. Communication of execution activities and assignment of responsibilities keep employees up to date about on-going strategy. Budgetary allocations are made available to carry out analyses that determine the best capacity building suited for the target population. Education Initiatives (2010) highlighted different ways of establishing teacher needs for capacity building which are: Student and teacher assessments; questionnaires; meetings; and classroom observations. Student and teacher assessments reveal weaknesses in past academic performances, teachers' mistakes and provide suggestions for recommended interventions for strategic capacity building. Background Questionnaires provide teachers' perception of what type of capacity building they most require based on their work experience. Focus group meetings with teachers, parents, education planners and managers can be carried out to identify specific areas that require capacity building. Classroom observations are carried out to observe teaching-learning interactions in the class environment for the identification of areas that require capacity building. These needs assessments methods give clear views of which level(s) of teachers require capacity building and which geographical location should be given priority. Teachers in the rural areas might need urgent interventions compared to their counterparts in the urban schools or vice versa. Needs analyses prevent waste of resources (time, money, materials, people) in investing on programs that target the wrong people, build wrong skills and eventually lead to failure in the implementation stage.

Secondly, designing capacity building programmes as explained by Gordon and Chadwick (2007) requires knowing the changes in capacity needed, identifying target participants, choosing the appropriate programmes that will fill the gaps identified from needs analysis. The contents of what needs to be taught are designed to lead to the desired impacts. Based on the specific capacity building required, the right resource persons, agencies or personnel consulting firms for the capacity building exercises are budgeted for, allocated resources and contacted early for adequate preparations. The relevance of capacity building programmes to teachers' work activities are also considered for the present and the future. Osuji (2014) emphasized that teacher capacity building should focus building teachers' knowledge and skills in learnercentered approaches as well as through welfare and empowerment. There are different categories of capacity building programs for different purposes. Capacity building programmes for functional capacities for basic education teachers improves pedagogy, application of ICT, knowledge of subject content etc. Capacity building programs which enhance technical capacities help teachers in classroom management, keeping records (statutory and non-statutory), planning lessons, pupils' evaluation etc. Also, programs that build behavioural capacities improve teachers' demeanor and their relationships with pupils, coworkers, parents, employers and the society at large.

Thirdly, determining the results requires education managers to outline futuristic results and impact of development programmes based on capacities built, utilized and quality of output. Capacities built include increased skills and additional competencies, changed attitudes of individual trainees, increased stock of knowledge, awareness, contacts and networks. Capacities utilized are the changes in practice resulting from

Studies

Vol. 2, No.2, pp. 85-90

2019

DOI. $10.53935 / 2641-533 x . v 2 i 2.108$

Funding: This study received no specific

financial support.

Received: 19 March 2019

Revised: 30 April 2019

Published: 26 August 2019

(c) 2019 by the authors; licensee Academic

Publishing Group 


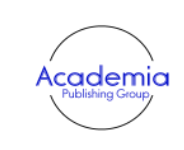

International Journal of Educational Studies

Vol. 2, No.2, pp. 85-90

2019

DOI: $10.53935 / 2641-533 x . v 2 i 2.108$

Funding: This study received no specific financial support.

Article History

Received: 19 March 2019

Revised: 30 April 2019

Accepted: 2 July 2019

Published: 26 August 2019

(C) 2019 by the authors; licensee Academic

Publishing Group utilization of the newly built capacities. Quality of output reflects in the accomplishment of all the objectives and goals of basic education evident in improvement of pupils' academic performance and other indicators of basic education.

SUBEB's' role of building teachers' capacity will deliver expected results and accomplish part of the strategies of 'Education for Change' if managers strategically work out the three processes before implementing capacity building programmes. The developed teachers are better at achieving objectives in the three domains of learning. Teachers' perception of the role of management in building their competencies as well as teachers' role toward achievement of education strategies and better quality delivery of basic education may positively influence their level of job satisfaction.

Teachers' job satisfaction may be viewed as their attitude to their teaching roles and responsibilities. Massari (2015) structured key factors of primary school teachers' job satisfaction in three levels namely micro- structural level (individual), meso-structural level (institutional) and macro-structural level (government policies). This means that teachers may experience varying levels of job satisfaction depending on how they rate their managers in terms of execution of strategies. Imeh (2018) highlighted the Job Characteristics Theory by Richard Hackman and Greg Oldham. The theory was based on the assumption that three critical psychological states (experienced meaningfulness, responsibility for outcomes and knowledge of results) are created by five core job dimensions (skill variety, task identity, task significance, autonomy and feedback). Positive personal work outcomes which include high job satisfaction are obtained as far as the critical psychological states are present. This theory is related to this study because executing strategic capacity building builds core job dimensions which may lead to teachers' experiencing critical psychological states and consequently, job satisfaction.

\section{Methods of Study}

This study adopted the correlational design. The area of this study is Akwa Ibom State of Nigeria. The population for the study comprised 12,566 teachers in 1,160 state-owned primary schools. A multi-stage approach which involved clustering and simple random sampling techniques were used in selecting six clusters out of 31 clusters and 1750 respondents for the study. Two instruments were used for the data collection. The Execution of Strategic Capacity Building Questionnaire (ESCBQ) was adapted from "Strategy Execution Barometer Questionnaire which assesses strategy execution based on eight dimensions - Strategy focus; Strategy communication; Initiative management; Individual objective setting; Skilled managers; Engaged people and performance-driven culture; Pay for performance; and Support for management. The instrument had eight items. The second instrument tagged "Teachers' Job Satisfaction Questionnaire" (TJSQ). Both instruments were assessed and rated by teachers as they assessed the SUBEB management as well as their job satisfaction. The instruments were face validated and subjected to Cronbach's Alpha Statistic with reliability coefficients of 0.83 and 0.79 respectively. A total of 1383 copies of questionnaire were completed and returned, thus accounting for a response rate of 79 percent. The null hypothesis was tested using the Pearson's Product Moment Correlation (PPMC). The correlation coefficient (r) was used to answer research questions.

\section{Results}

Research Question: What is the relationship between SUBEB's execution of strategic capacity building and teachers' job satisfaction in Akwa Ibom State, Nigeria?

Table-1. PPMC for SUBEB's execution of strategic capacity building and teachers' job satisfaction ( $\mathrm{N}=1383)$

\begin{tabular}{llllll}
\hline Variables & $\sum \mathbf{X}$ & $\sum \mathbf{X}^{\mathbf{2}}$ & $\sum \mathbf{x y}$ & r-cal Remark \\
& $\sum \mathbf{Y}$ & $\sum \mathbf{Y}^{\mathbf{2}}$ & & & \\
\hline Execution of strategic Capacity Building & 29296 & 2383519 & 135523 & 0.418 Moderate relationship \\
Job Satisfaction & 106227 & 8808337 & & & \\
\hline
\end{tabular}

Table 1 shows the nature and strength of relationship between SUBEB's execution of strategic capacity building and teachers' job satisfaction. The result reveals that the coefficient $r$ of .418 is moderate in nature and in a positive direction. This therefore means that there is a positive relationship between SUBEB's execution of strategic capacity building and teachers' job satisfaction. The positive relationship occurs 
because the more capacity building programmes are strategically executed towards a successful implementation of education strategies, the more teachers are satisfied with their jobs.

Hypothesis 1: There is no significant relationship between SUBEB's execution of strategic capacity building and teachers' job satisfaction in Akwa Ibom State, Nigeria.

Table-2. Significance of the PPMC between SUBEB's execution of strategic capacity building and teachers' job satisfaction $(\mathrm{N}=1383)$.

\begin{tabular}{lllllll}
\hline Variables & $\sum \mathbf{X}$ & $\sum \mathbf{X}^{\mathbf{2}}$ & $\sum \mathbf{x y}$ & r-cal & r-crit & Decision at P<0.05 \\
& $\sum \mathbf{Y}$ & $\sum \mathbf{Y}^{\mathbf{2}}$ & & & & \\
\hline Execution of strategic Capacity Building & 29296 & 2383519 & 135523 & 0.418 & 0.062 & Significant \\
Job Satisfaction & 106227 & 8808337 & & & & \\
\hline
\end{tabular}

Note: $\mathrm{df}=1381$

The data in Table 2 revealed that calculated r-value of .418 is greater than the critical r-value of .062 at .05 alpha levels with 1381 degrees of freedom. The null hypothesis that there is no significant relationship between SUBEB's execution of strategic capacity building and teachers' job satisfaction is rejected. Therefore, there is a significant relationship between SUBEB's execution of strategic capacity building and teachers' job satisfaction in Akwa Ibom State.

\section{Discussion of Findings}

The findings revealed a significant relationship between SUBEB's execution of strategic capacity building and teachers' job satisfaction in Akwa Ibom State. The more teachers' capacity-building programmes are designed and executed towards implementation and achievement of educational strategies, the more they (the teachers) will feel satisfied in their job. The more SUBEB management focuses on the objective of retraining teachers for quality delivery, the more teachers will value management's efforts in improving their personal and work outcomes which results to high job satisfaction. This builds teachers' confidence in SUBEB management thereby increasing their overall level of job satisfaction.

The importance of strategy communication in the execution process paints a clear picture for teachers to understand the need for execution of strategic capacity building, their co-operation in giving relevant information for its execution and benefits of future implementation. This significantly relates to teachers' job satisfaction because they get to experience meaningfulness of their work and experience responsibility for outcomes of execution process. This is in agreement with the Job Characteristics theory because the experiences are the critical psychological states that lead to job satisfaction.

The findings of this study also confirm that the more teachers' ideas are incorporated in the design of their capacity-building programmes and the use of school-based information for needs analyses and documentation, the more the level of job satisfaction experienced among teachers. Teachers will appreciate and feel more satisfied with capacity-building programmes that address the problems well-known and experienced by them. This builds a variety of capacities (behavioural, technical and functional) needed for the multi-faceted nature of the teaching job with a visible and achievable outcome; and strategy execution is about achieving results. This relates to teachers' affective reactions to their jobs towards either experiencing positive internal feelings when capacity-building programme makes them more effective on the job or experience negative internal feelings if capacity-building program cannot improve the status-quo of the basic education programme. The internal feelings give rise to satisfaction in different job facets which determine the overall measure of the degree to which teachers are satisfied with their jobs. This finding is corroborated by the findings of Akpan and Ita (2015) who discovered that teacher participation in induction programmes, ICT trainings and participation in seminars/workshops significantly related to quality universal basic education.

Internatior
Studies

Vol. 2, No.2, pp. 85-90

2019

DOI: $10.53935 / 2641-533 x . v 2 i 2.108$

Funding: This study received no specific

financial support.

Article History:

Received: 19 March 2019

Revised: 30 April 2019

Accepted: 2 July 2019

Published: 26 August 2019

(c) 2019 by the authors; licensee Academic

Publishing Group

\section{Conclusion and Recommendations}

It is concluded that SUBEB's execution of strategic capacity building is associated with teachers' job satisfaction. Incorporating strategy execution into strategy management process makes for a more successful implementation of teachers' capacity building for quality delivery of basic education. Relating the findings to the problem of the study has emerged with solutions that will strengthen and improve Nigeria's basic education programme with evidence of achievement of the on-going 'Education for Change' strategic plans, 
improved global reports and rankings, as well as better work outcomes that result from high levels of teachers' job satisfaction.

Based on this conclusion, it was recommended that the management of SUBEB should carry out detailed analyses of needs assessment for teachers' capacity building in order to target the right trainings for the right participants. It is also expedient and hence recommended that SUBEB management design the content of capacity building programs which must address deficiencies in teachers' professional skills, knowledge and conduct so as to enhance their performance and quality delivery to learners.

\section{References}

Akon, G. (2016). Nigeria's out of school population hits 11.4 million. The Abuja Inquirer. Retrieved from http://www.theabujainquirer.com/?page $=1607 \&$ get $=1607$.

Akpan, C., \& Ita, A. (2015). Teacher professional development and quality universal basic education in Lagos State, Nigeria. Global Journal of Arts, Humanities and Social Sciences, 3(9), 65-76.

Favaro, K. (2015). Strategy execution: Defining strategy, implementation and execution. Retrieved from https://hbr.org/2015/03/defining-strategy-implementation-and-execution.

Federal Republic of Nigeria. (2004). The compulsory, free, universal basic education act 2004 and other related matters. Abuja: GAM International Investments Limited.

Flander, J. D. (2015). Strategy execution 2030. How to execute strategy like a pro. Retrieved from https://www.casrilanka.com/casl/images/stories/content/business/post/jeroen_de_flander_how_to_execute_strategy_li ke_a_pro.pdf.

Gordon, J., \& Chadwick, K. (2007). Impact assessment of capacity building and training: assessment framework and two case studies (Vol. 44): Australian Centre for International Agricultural Research.

Imeh, A. I. (2018). Strategy execution of the state universal basic education board and teachers' job satisfaction in Akwa Ibom State. Ph.D Thesis, University of Uyo, Uyo.

Massari, G.-A. (2015). Key factors of preschool and primary school teachers job satisfaction. Acta Paediatrica, 5, 27-40.

Osuji, C. U. (2014). Capacity building of teachers as a strategy in bridging the gap in Nigerianeducational system. African Education Indices, $7(1), 1-15$.

Pederson, K. L. (2008). Cracking the code of strategy execution. MSc Dissertation. Copenhagen Business School, Denmark.

Performance Factory. (2010). The strategy execution research report 2009/2010. Retrieved from http://jeroendeflander.com/wpcontent/uploads/2014/11/StrategyExecutionResearchReportFreeAbstract.pdf.

Psacharopoulous, G. (2016). Post-2015 development agenda: Nigeria perspectives in education. Tewksbury, Massachusetts, United States: Prepared to the Federal Government of Nigeria through Copenhagen Consensus Center.

Rosenzweig, C., \& Tubiello, F. N. (2007). Adaptation and mitigation strategies in agriculture: An analysis of potential synergies. Mitigation and Adaptation Strategies for Global Change, 12(5), 855-873.

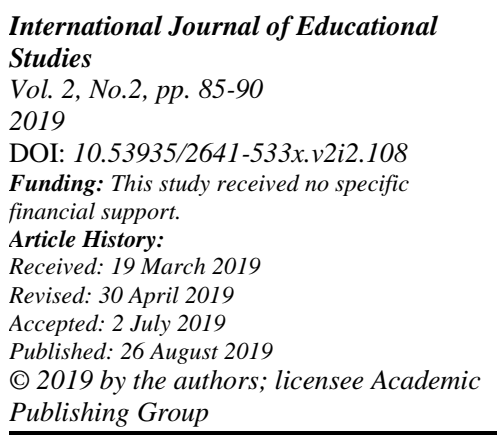

90 